\title{
Mortality trends in Acute Coronary Syndrome In Sahid Gangalal National Heart Centre
}

Dr S Rajbhandari, Dr M B.K.C., Dr D Sharma, Dr R Malla, Dr S Regmi, Dr Y, R. Limbu, Dr Arun Maskey, Dr A Rajbhandari, Dr Y Bhatt, Dr S Kansakar

At the beginning of $20^{\text {th }}$ century cardiovascular disease accounted for less than $10 \%$ of mortality worldwide. It has increased to $50 \%$ in the developed and $25 \%$ in the developing world at the end of the century.

There has been steady decline in mortality due to acute myocardial infarction resulting from development of Coronary Care Unit, aspirin, beta blockade and Thrombolysis.

328 cases of acute coronary syndrome were admitted in CCU, (Jan 03 to Dec 03) out of which 227 (69.2\%) were male and 91 (30.8\%) were female.

\section{Table 1: Acute STEMI admission in CCU}

\begin{tabular}{|c|c|c|c|c|c|}
\hline Diagnosis & Male & Female & Total & STK given & Deaths(\%) \\
\hline Inferior wall Ml* & 71 & 13 & 84 & 29 & $5(5.9)$ \\
\hline Anterior Ml & 21 & 9 & 30 & 8 & $2(6.6)$ \\
\hline $\begin{array}{l}\text { Extensive } \\
\text { Anterior }\end{array}$ & 20 & 3 & 23 & 7 & 0 \\
\hline Anteroseptal & 12 & 3 & 15 & 1 & 0 \\
\hline Lateral wall & 5 & 2 & 7 & 0 & 0 \\
\hline Total & 129 & 30 & 159 & 45 & $7(4.4)$ \\
\hline
\end{tabular}

${ }^{*} \mathrm{RV}$ infarction $-=7$, Posterior wall $\mathrm{MI}=3$.

We can see that a total of 159 ST elevation Ml were admitted with the highest number taken by inferior $94(52.8 \%)$. Out of them (STEMI) more than quarter recalved streptokinase $(28.3 \%)$. The mortalily was 7 (4.4\%). 
Table 2: NSTEMI and Unstable Angina admission in CCU

\begin{tabular}{|l|l|l|l|l|}
\hline Diagnosis & Male & Female & Total & Deaths(\%) \\
\hline NSTEMI & 20 & 7 & 27 & $1(3.7)$ \\
\hline Unstable Agnina & 78 & 54 & 132 & $1(0.7)$ \\
\hline Total & 98 & 61 & 159 & $2(1.3)$ \\
\hline
\end{tabular}

A total of 152 cases of unstable angina and NSTEMI were admitted with only 2 deaths among them ie mortality of $1.3 \%$,

Table 3: Comparison of last 3 years CCU admissions and mortality

\begin{tabular}{|l|l|l|l|}
\hline Year & Number of admissions & Mortality & $(\mathbf{\%})$ \\
\hline $2001-2002$ & 63 & 6 & 9.5 \\
\hline $2002-2003$ & 194 & 15 & 7.7 \\
\hline $2003-2004$ & 328 & 9 & 4.1 \\
\hline
\end{tabular}

